\title{
Use of Fluorescence-Labelled Macroinitiator to Investigate Nucleation Mechanism in Nitroxide-Mediated Crosslinking Polymerization in Aqueous Miniemulsion
}

\author{
By Per B. ZetTERLUND, Md. Nur ALAM, and Masayoshi OKUBO*
}

\author{
KEY WORDS: Nitroxide-mediated Polymerization / Miniemulsion / Crosslinking / Kinetics / Controlled/living /
}

Controlled/living radical polymerization (CLRP; e.g. nitroxide-mediated polymerization (NMP)) enables synthesis of macromolecules with well-defined structure. ${ }^{1}$ Current challenges in CLRP include implementation in heterogeneous systems. ${ }^{2,3} A b$ initio emulsion CLRP is difficult due to problems with colloidal instability and transport of control agent between monomer droplets and polymer particles, but approaches based on nucleation via macroinitiator self-assembly have been successful. ${ }^{3}$ Miniemulsion CLRP is more straightforward because particle nucleation and control agent diffusion across the aqueous phase is avoided. ${ }^{4}$ Ideally, each monomer droplet is converted to a particle. Deviation from this ideality in miniemulsion CLRP may lead to compromised control/livingness. Secondary nucleation causes formation of polymerization loci without control agent, i.e. lower control/livingness and broader particle size distribution.

Crosslinking CLRP results in highly homogeneous polymer networks, ${ }^{5}$ and crosslinking CLRP in heterogeneous systems affords crosslinked polymer particles of high homogeneity and different mechanical properties compared to particles prepared by non-living crosslinking polymerizations. ${ }^{6}$

The present contribution describes a novel approach based on macroinitiator fluorescence (FL)-labelling in nitroxide-mediated crosslinking radical polymerization in aqueous miniemulsion of styrene $(\mathrm{S})$ and divinylbenzene (DVB) to confirm the absence of secondary nucleation.

\section{EXPERIMENTAL}

\section{Materials}

$\mathrm{S}$ was distilled under reduced pressure. Benzoyl peroxide was recrystallized using chloroform/methanol. 2,2,6,6-Tetramethylpiperidinyl1-oxy (TEMPO), sodium dodecylbenzenesulfonate (SDBS) and 1-pyrenylmethyl methacrylate (Polysciences Inc.) were used as received.

\section{Polymerizations}

PS-TEMPO macroinitiator was prepared as in the literature ${ }^{7}\left(M_{\mathrm{n}}=\right.$ 2650, $\left.M_{\mathrm{w}} / M_{\mathrm{n}}=1.12\right)$. The FL-labelled macroinitiator $\left(\mathrm{PS}_{\mathrm{FL}}-\mathrm{TEMPO}\right)$ was prepared in the same way in the presence of $0.035 \mathrm{~mol} \%$ 1-pyrenylmethyl methacrylate. The obtained polymer was dissolved in toluene followed by filtration to remove unreacted FL monomer, precipitated in methanol and dried $\left(M_{\mathrm{n}}=2350, M_{\mathrm{w}} / M_{\mathrm{n}}=1.10\right)$.

Miniemulsion polymerizations $\left(125^{\circ} \mathrm{C}\right)$ : A solution of $\mathrm{S}(0.74 \mathrm{~g})$, DVB $(9.5 \mathrm{mg})$, PS-TEMPO (30 mg) and PS $\mathrm{FL}_{\mathrm{FL}}$ TEMPO (13.6 mg) was mixed with an aqueous solution of SDBS (14.25 g water, $35 \mathrm{mg}$ SDBS), and emulsified with a Ultrasonic Homogenizer (Nissei, US-600T) for $12 \mathrm{~min}$ at $0^{\circ} \mathrm{C}$. Polymerizations were carried out in degassed glass ampules $(4 \mathrm{~mL} /$ ampule). Bulk copolymerization of S/DVB $\left(125^{\circ} \mathrm{C}\right)$ was carried out based on the organic phase of the above recipe. Solution polymerization $\left(125^{\circ} \mathrm{C}\right)$ : $\mathrm{S}(1.5 \mathrm{~g})$, toluene $(1.5 \mathrm{~g})$, PS-TEMPO $(30 \mathrm{mg})$ and $\mathrm{PS}_{\mathrm{FL}}$-TEMPO $(13 \mathrm{mg})$.

\section{Measurement}

Particle size distribution: Dynamic light scattering (DLS-7000, Otsuka Electronics). Conversion: Gas chromatography (Shimadzu Corporation). Molecular weight distributions (MWD): Gel permeation chromatography with refractive index (TOSOH RI-8020/21) and FL detection (JASCO FP2020 Plus) relative to linear PS.

\section{RESULTS AND DISCUSSION}

The RI detector response is proportional to the instantaneous mass of polymer passing through the detector, but the FL detector response is proportional to the number of FL units. Direct comparison between the detector responses is therefore not always possible. Due to the low FL content, most $\mathrm{PS}_{\mathrm{FL}}$-TEMPO chains do not contain any FL units. It is however not a requirement that all chains contain an FL unit, because the overall number of chains is so high that the FL-labelled chains constitute a statistically representative sample (thus, both PS-TEMPO and $\mathrm{PS}_{\mathrm{FL}}{ }^{-}$ TEMPO were employed simultaneously due to the high cost of FL). The average number of FL units in chains of a given chain length is proportional to the chain length (number of FL units per chain $<1$ ), and thus the polymer mass is proportional to the number of FL units. The MWDs of the PS $\mathrm{FL}_{\mathrm{FL}}$-TEMPO macroinitiator obtained from the RI and FL detectors were therefore identical (not shown).

In S/DVB crosslinking copolymerization initiated by PS-TEMPO/ $\mathrm{PS}_{\mathrm{FL}}$-TEMPO, a crosslinked molecule of high MW contains numerous macroinitiator segments (one per primary chain). The average number of FL units in a crosslinked molecule is therefore approximately proportional to its $\mathrm{MW}$, and the FL response is thus approximately proportional to the RI response, making direct comparison between the FL- and RI-derived MWDs possible.

Figure 1a shows RI- and FL-derived MWDs in the TEMPO-mediated polymerization of S/DVB in bulk. As anticipated, the MWDs are close to identical at $\mathrm{MW}>10^{4} \mathrm{~g} / \mathrm{mol}$. Overestimation in the low MW region by FL detection is caused by molecules containing only one macroinitiator segment, for which the FL content in the molecule is not proportional to its overall MW (the FL-content is governed only by the macroinitiator-derived segment). This is illustrated in Figure 1b, which shows MWDs of linear PS in solution polymerization with PS-TEMPO/PS $\mathrm{FL}_{\mathrm{FL}}$-TEMPO. The low MW region is overestimated and the high $\mathrm{MW}$ region is underestimated by FL detection, giving the appearance of the peak having been shifted along the $\log M$ axis. In this case, the FL-derived MWD is incorrect because the FLresponse is not proportional to polymer mass. The low MW peak in the FL MWD is dead macroinitiator. The FL-detector has higher sensitivity towards low MW chains than the RI-detector.

The main objective of the present work has been to establish whether secondary nucleation is significant in TEMPO-mediated miniemulsion copolymerization of S/DVB. Very significant spontaneous radical gen-

Department of Chemical Science and Engineering, Graduate School of Engineering, Kobe University, Kobe 657-8501, Japan

${ }^{*}$ To whom correspondence should be addressed (Tel \& Fax: +81-78-803-6161, E-mail: okubo @ kobe-u.ac.jp). 

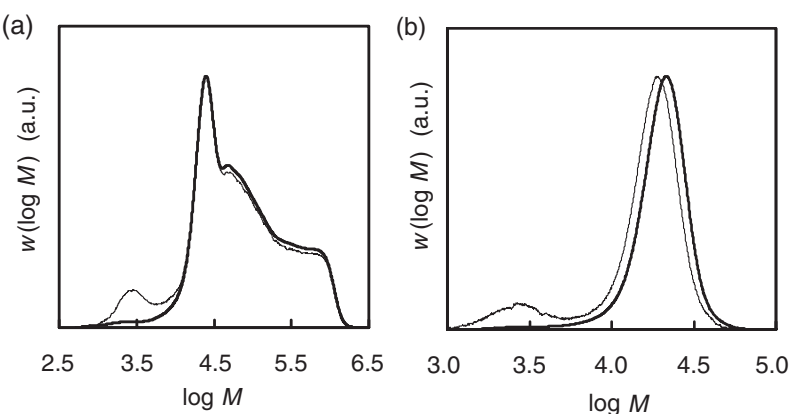

Figure 1. MWDs by RI (thick line) and FL (thin line) detection in TEMPOmediated (co)polymerization at $125^{\circ} \mathrm{C}$ : (a) S (99 mol \%) and DVB ( $1 \mathrm{~mol} \%$ ) in bulk at $44 \% \mathrm{~S}$ conv.; (b) Solution ( $50 \mathrm{wt} \%$ toluene) polymerization of $\mathrm{S}$ at $38 \%$ conv.
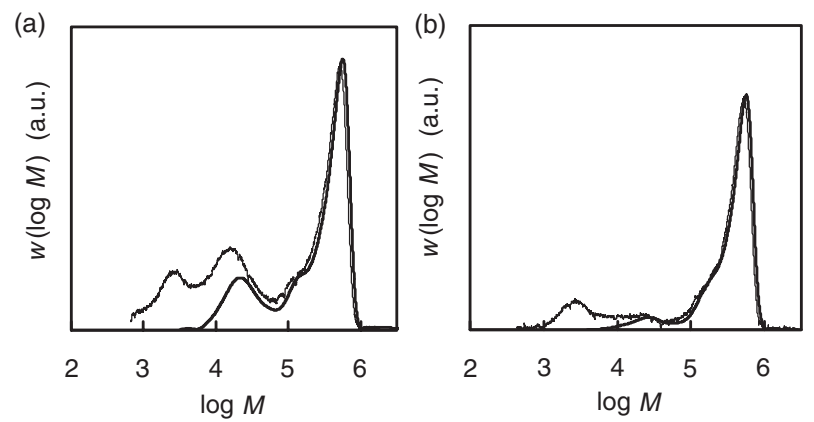

Figure 2. MWDs by $\mathrm{RI}$ (thick line) and $\mathrm{FL}$ (thin line) detection in TEMPOmediated copolymerization of $\mathrm{S}(99 \mathrm{~mol} \%) / \mathrm{DVB}(1 \mathrm{~mol} \%)$ in miniemulsion at $125^{\circ} \mathrm{C}$ at (a) 64 and (b) $86 \%$ S conv.

eration occurs in aqueous $\mathrm{S}$ miniemulsions at $125^{\circ} \mathrm{C}$ (higher than in bulk), ${ }^{8}$ and secondary nucleation is thus conceivable. Secondary nucleation, i.e. formation of polymer particles by homogeneous or micellar nucleation, would result in polymer not containing any $\mathrm{PS}_{\mathrm{FL}}$-TEMPO (the number of FL units would no longer be approximately proportional to the polymer $\mathrm{MW}$ ) because $\mathrm{PS}_{\mathrm{FL}}$-TEMPO is too hydrophobic to exit monomer droplets. In other words, if secondary nucleation is significant, polymer visible by RI but not by FL would be present.

Figure 2 shows MWDs from RI and FL detection in miniemulsion copolymerization of S/DVB initiated by PS-TEMPO/PS $\mathrm{FL}_{\mathrm{FL}}$-TEMPO. The result is similar to that obtained in bulk (Figure 1a), i.e. the two MWDs are close to identical for $\mathrm{MW}>10^{4.5} \mathrm{~g} / \mathrm{mol}$, indicating that secondary nucleation is negligible. The particle size distributions in miniemulsions are often broad, and it is difficult to discern from such data whether secondary nucleation occurs. The particle number (size) remained approximately constant with conversion $\left(d_{\mathrm{n}} \approx 57 \mathrm{~nm} ; d_{\mathrm{w}} \approx 70 \mathrm{~nm}\right)$. Coagulation would lead to combination of secondary particles with particles from droplet nucleation, and subsequent crosslinking would result in FL-incorporation also in polymer originally from secondary particles. However, this would disrupt the approximate proportionality between MW and FL-content, i.e. the FL- and RI-derived MWDs would not be identical. The MWDs are relative to linear PS standards and not absolute - this does not, however, affect the present conclusions.

In summary, we have demonstrated how the particle formation mechanism in crosslinking NMP in miniemulsion can be investigated by use of a novel FL-labelling approach. For the TEMPO-mediated miniemulsion copolymerization of S/DVB under the present conditions, particle formation occurs exclusively via monomer-droplet nucleation.

Acknowledgment. This work was supported by a Grant-in-Aid for Scientific Research (17750109) and a Grants-in-Aid program grant ((C) 19550125) from the Japan Society for the Promotion of Science, a Kobe University Takuetsu-shita Grant, and a Monbukagakusho from the Ministry of Education, Science, Sports, and Culture of Japan.

Received: November 26, 2007

Accepted: December 29, 2007

Published: February 19, 2008

\section{REFERENCES}

1. W. A. Braunecker and K. Matyjaszewski, Prog. Polym. Sci., 32, 93, (2007).

2. a) J. Qiu, B. Charleux, and K. Matyjaszewski, Prog. Polym. Sci., 26, 2083, (2001).

b) M. F. Cunningham, Prog. Polym. Sci., 27, 1039, (2002).

c) J. B. McLeary and B. Klumperman, Soft Matter, 2, 45, (2006).

3. a) M. Save, Y. Guillaneuf, and R. G. Gilbert, Aust. J. Chem., 59, 693, (2006).

b) B. Charleux and J. Nicolas, Polymer, 48, 5813, (2007).

4. a) P. B. Zetterlund, T. Nakamura, and M. Okubo, Macromolecules, 40 , 8663, (2007).

b) H. Maehata, C. Buragina, and M. Cunningham, Macromolecules, 40, 7126, (2007).

c) L. Bombalski, K. Min, H. C. Dong, C. B. Tang, and K. Matyjaszewski, Macromolecules, 40, 7429, (2007).

d) Y. Kagawa, P. B. Zetterlund, H. Minami, and M. Okubo, Macromolecules, 40, 3062, (2007).

5. a) N. Ide and T. Fukuda, Macromolecules, 32, 95, (1999). b) F. Isaure, P. A. G. Cormack, S. Graham, D. C. Sherrington, S. P. Armes, and V. Butun, Chem. Commun., 1138, (2004).

c) A. R. Wang and S. Zhu, Polym. Eng. Sci., 45, 720, (2005).

d) H. Gao, K. Min, and K. Matyjaszewski, Macromolecules, 40, 7763. (2007).

6. a) T. Norisuye, T. Morinaga, Q. Tran-Cong-Miyata, A. Goto, T. Fukuda, and M. Shibayama, Polymer, 46, 1982, (2005).

b) D. Taton, J. F. Baussard, L. Dupayage, J. Poly, Y. Gnanou, V. Ponsinet, M. Destarac, C. Mignaud, and C. Pitois, Chem. Commun. 1953, (2006).

c) J. K. Oh, C. Tang, H. Gao, N. V. Tsarevsky, and K. Matyjaszewski, J. Am. Chem. Soc., 128, 5578, (2006).

d) Y. Saka, P. B. Zetterlund, and M. Okubo, Polymer, 48, 1229, (2007).

e) T. Tanaka, T. Suzuki, Y. Saka, P. B. Zetterlund, and M. Okubo, Polymer, 48, 3836, (2007).

7. P. B. Zetterlund, Md. N. Alam, H. Minami, and M. Okubo, Macromol. Rapid Commun., 26, 955, (2005).

8. Md. N. Alam, P. B. Zetterlund, and M. Okubo, Polymer, in press 